Journal of Engineering and Applied Sciences 14 (Special Issue 6): 9379-9395, 2019

ISSN: 1816-949X

(C) Medwell Journals, 2019

\title{
Numerical and Experimental Study into the Design of the Rolling Machine's Shear Pin
}

\author{
Zainab M. Hameed and Riyah N. Kiter \\ Department of Mechanical Engineering, University of Anbar, Anbar, Iraq \\ wmowm55@gmail.com
}

\begin{abstract}
This research is dedicated to design and manufacture the mechanical fuse shear pin, especially, that used in the rolling machine of the General Company for Copper and Mechanical Industries in Iraq. Finite element analysis that performed by ANSYS Software is used to accomplish the numerical part of this study. The maximum normal stress theory is selected as the failure criterion. A gray cast iron material is employed in shear pin preparing. To check shear pin's specimens, a completed testing system is designed and manufactured. Consequently, detailed tables are presented to select a suitable geometry of shear pin's notch for any value of torque requires by the rolling machine. Also, the effect of the notch angle, notch depth, notch tip radius, notch shape and the ultimate tensile strength on the value of the torque at the fracture is obtained and explained by tables, sketches and contours. A comparison between the numerical and experimental works is shown an acceptable result. The error between the ANSYS and the experimental data is not exceeding $(4 \%)$.
\end{abstract}

Key words: Shear pin, mechanical fuse, circumferential notch, V-notch, material, notch tip radius

\section{INTRODUCTION}

The importance of machines is highly increased in the current world. Manufacturing and maintenance of machinery parts are not easy operations. Plenty of efforts and funds should be used. So, it is important to save the expensive parts of machines from damage.

One of the reasons that causes many cases of damage is the overloads which generate in different ways. Large machines are usually involved a power source and to transmit the power to the other part of the machine, shaft-hub components are mostly used. To protect the worthy machine's portions, a mechanical fuse locates at the shaft-hub joint to stop the machine operation at overloads (Fig. 1).

There are various types of the mechanical fuse. Shear pin is one of these classifications of the mechanical fuses. It is not the most accurate one but it is cheap and so easy to prepare comparing with others and in some situations, the machine is complicated and the replacement of the ancient mechanical fuse system is not convenient. In this study, a shear pin is the focus of the attention, especially that used in the rolling machine (Fig. 2).

Shear pin that concerned in this study is a sacrificed device consists from round bar with a groove. It is located in a drilled channel penetrated the joints of the shaft-hub of the concerned roller machine. The angle, depth, shape and tip radius of the groove determine the fracture stress.
When the load exceeds the determined value, the shear pin is fractured preventing the machine destruction and replaced by another one.

Sankar et al. (2011) checked the failure of the shear pin element which connects the generator and gear box in a wind turbine and showed that the crack propagation in the shear pin is caused by cyclic fatigue. Azevedo et al. (2009) experimentally and numerically studied the shear pin of the Coaracy Nunes hydroelectric power plant in Brazil and indicated that the fatigue was the reason of the stable crack propagation. And the bending stress presence strongly increased the value of the stress concentration factor. Tha et al. (2008) experimentally studied the effect of inclusions on EN 19 steel (high quality alloy steel with tensile strength) shear pin under fatigue loading and found that the inclusions, located near the notch and involved in the steel, caused the initiation of fatigue crack. Smith et al. (2007) tried to redesign of a shear pin under the effect of cycling bending loads for motor and gearbox drives a flocculator train and the premature pin failure is found to cause by cyclic fatigue which produced by misalignment between driven and driving coupling elements (Fig. 3). In this research, the shear pin of the rolling machine the General Company for Copper and Mechanical Industries in Iraq will redesign and manufacture.

Problem statement: The rolling machine of the mentioned company in Iraq (which shown in Fig.4) faces some cases

Corresponding Author: Zainab M. Hameed, Department of Mechanical Engineering, University of Anbar, Anbar, Iraq, wmowm55@gmail.com 


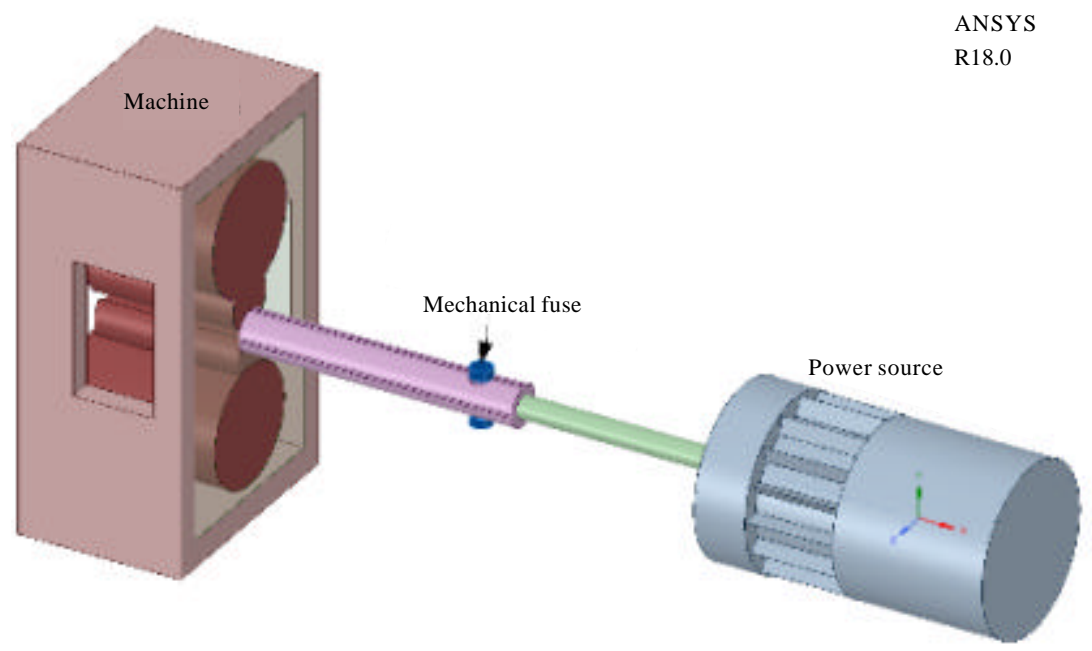

Fig. 1: Sketch explains the location of the mechanical fuse between the power source and the machine

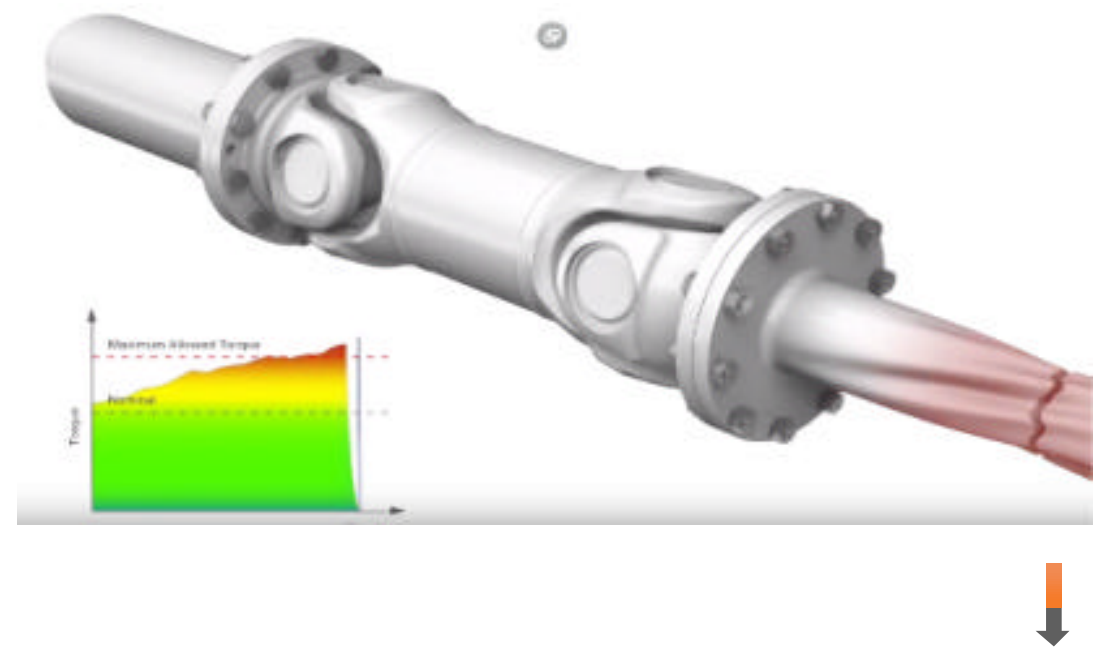

Fig. 2: Sketch shows the defect of overload on the machine part without fuse

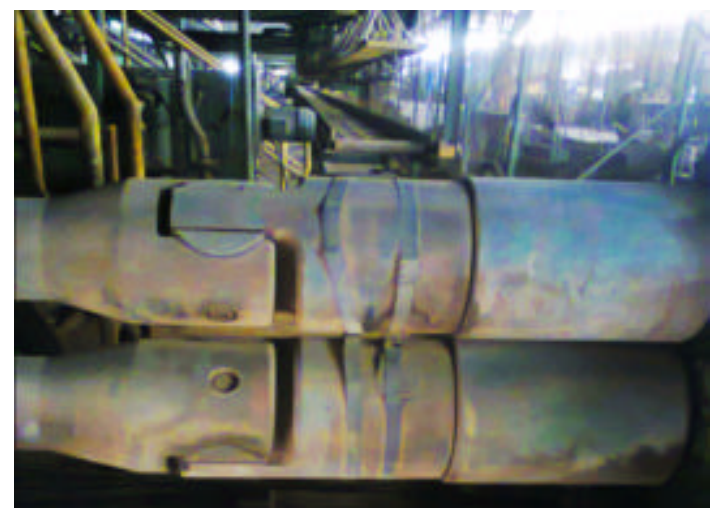

Fig. 3: Hub-shaft joint in rolling machine in the mention company

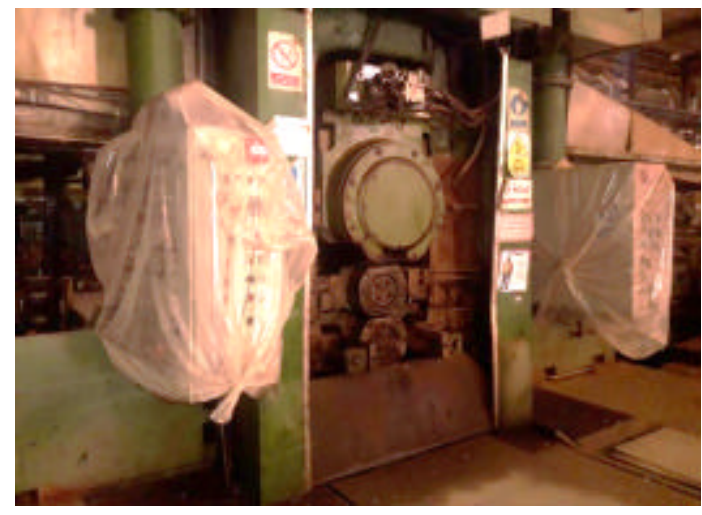

Fig. 4: Side view of the roller part of the concerned rolling machine 
of overloads. So, the using of shear pin is necessary. The shear pin that use in this machine exports from another country. Due to the security situation in Iraq, the difficult exporting process and the relatively high price, a proposal is generated to locally manufacture this shear pin element from available and very cheap material.

For some reasons, it was difficult to operate the required rolling machine to test the produced shear pins. So, a special system is designed and manufactured to test the shear pin patterns. Due to the high power (1 MW) of rolling machine's motor, it is not possible to use the same motor in our system. So, the manufactured patterns of shear pins have smaller dimensions than the real shear pins that used in rolling machine. But it also, tests numerically by ANSYS Software program. Consequently in this study, there are two patterns. The first for the rolling machine. The second for the testing system (Fig. 5).

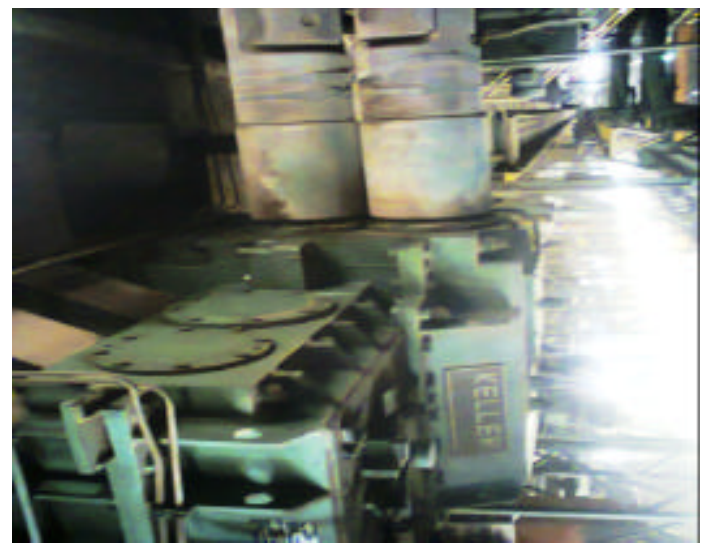

Fig. 5: Motor part of rolling machine concerned in this study

\section{MATERIALS AND METHODS}

The aim of the study is producing a mechanical fuse shear pin from brittle material locally provided, cheap in price, widely available and easy to prepare. So, the gray cast iron is the suitable choice. The gray cast iron rods prepare by casting process. Where the raw metal melts in a furnace to temperature reaches to $1,200^{\circ} \mathrm{C}$. Then the molten metal pours into the casting molds and leaves to cool to produce the rods that take to lathing process and then to tensile test (Fig. 6).

Tensile test and chemical analysis are achieved to investigate the mechanical and chemical properties for gray cast iron material. This tensile test was carried out for four specimens of gray cast iron in university of technology with the metallically and production department at room temperature by using computerized (WDW-200 E-200 kN) at constant crosshead speed $(1 \mathrm{~mm} / \mathrm{min})$. The range of the ultimate tensile strength is (280-290 MPa). To examine the gray cast iron structure, the chemical analysis is important. Table 1 presents the data of chemical analysis (Aziz, 2018).

Finite element analysis: The numerical part of this research is carried out by ANSYS Software based on finite element method. Maximum normal stress theory is used for this study. It states that the failure of the brittle material occurs when the maximum principal

\begin{tabular}{ll}
\multicolumn{2}{l}{ Table 1: Chemical composition of gray cast iron material } \\
\hline Elements & Materials weight \\
\hline $\mathrm{C}$ & 3.50 \\
$\mathrm{Si}$ & 2.24 \\
$\mathrm{P}$ & 0.26 \\
$\mathrm{~S}$ & 0.12 \\
$\mathrm{Mn}$ & 0.76 \\
$\mathrm{Fe}$ & Reminder \\
\hline
\end{tabular}

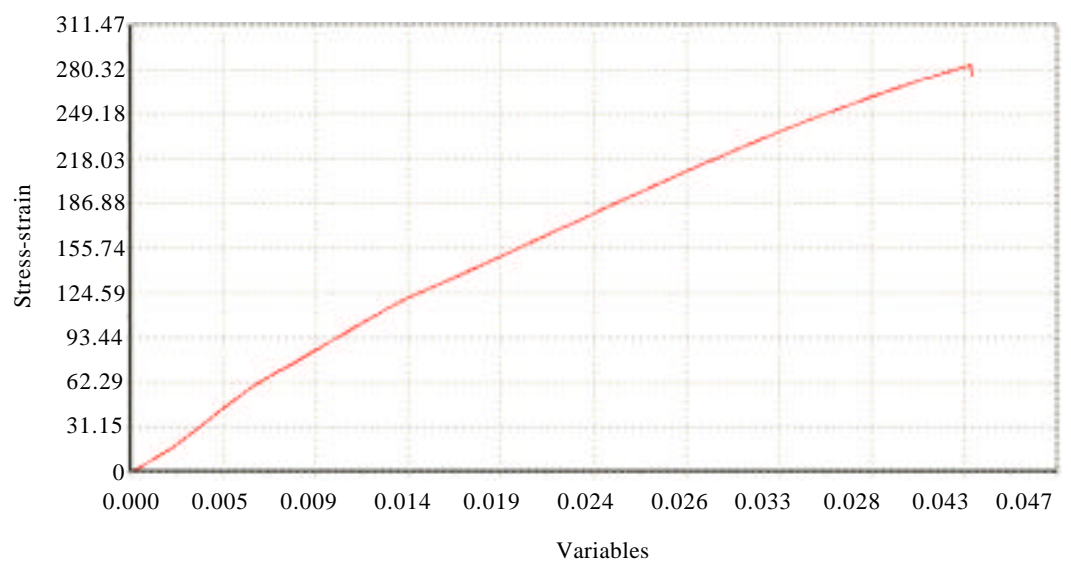

Fig. 6: Stress-strain curve from tensile test of the gray cast iron 


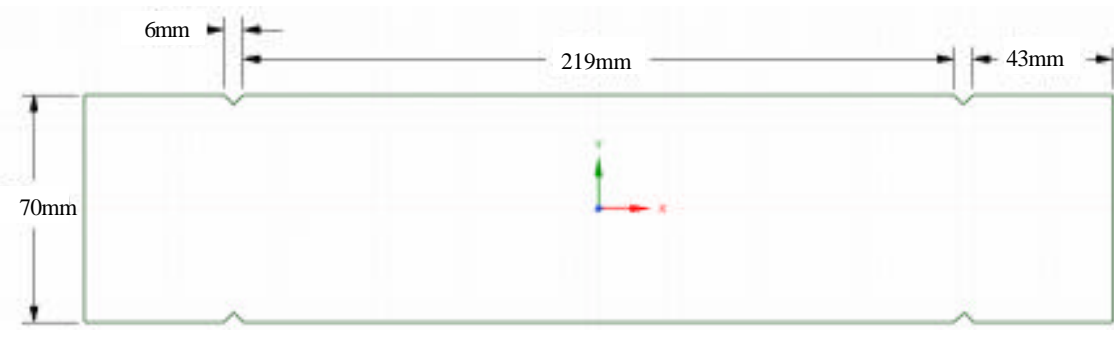

Fig. 7: 2D sketch shown the general dimension of $\mathrm{V}$-notched shear pin used in the rolling machine

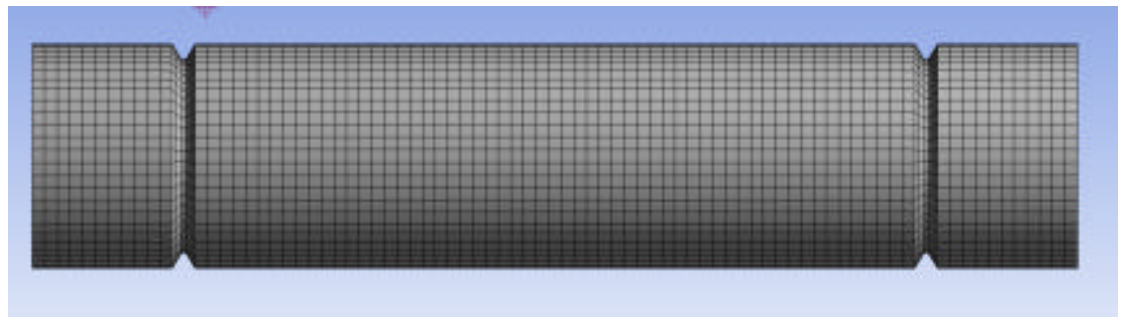

Fig. 8: The general shape of the applied mesh of the rolling machine shear pin

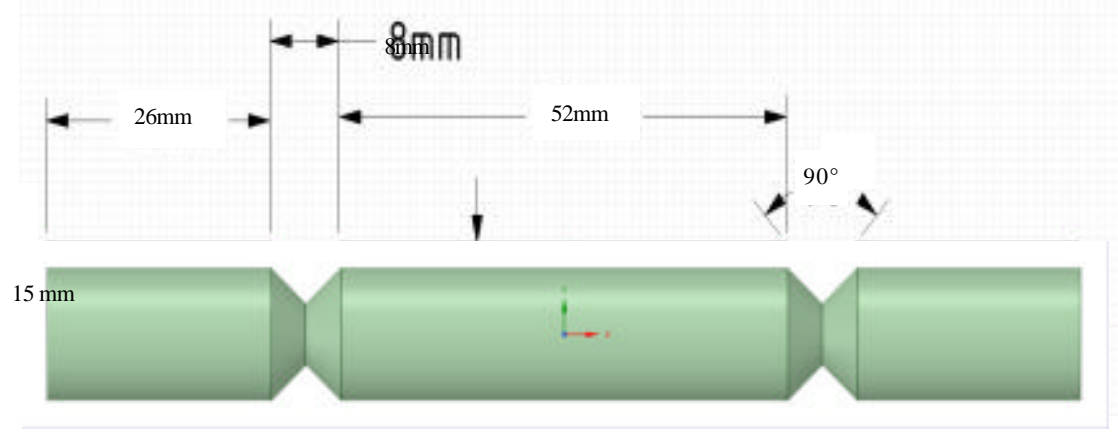

Fig. 9: The dimension of the manufactured shear pin

stress value becomes greater than the value of the ultimate tensile strength (Wu and Liu, 2008; Smith, 2001).

The dimensions of the hub-shaft of the rolling machine and the channel of the shear pin impose a determined geometry on the shear pin as shown in Fig. 7. After design process, the suitable mesh is done with $0.004 \mathrm{~m}$ element size and 203335 nodes. Then the torque is applied on the center part of shear pin at z-axis and the terminal parts place under fixed support. The value of the torque that uses to apply should cause a maximum principal stress equals $(300 \mathrm{MPa})$ which is greater than the ultimate tensile strength $(290 \mathrm{MPa})$ at the notch tip to produce the fracture.

The groove depth, angle and tip radius are changed for every tempt. The values of depth that experimented are $(2-6 \mathrm{~mm})$, the angles are $(30,37,60,90,120)$ and the tip radii are $(0,0.25,0.5,0.75,1 \mathrm{~mm})$ with $70 \mathrm{~mm}$ diameter of the cross-section for the rolling machine's shear pin. The notch dimensions for the testing machine's shear pin are $\left(30,60,74,90^{\circ}\right)$ for notch angle, $(2-6 \mathrm{~mm})$ for notch depth and $(0,0.25,0.5,0.75$ and $1 \mathrm{~mm})$ for tip radius with $15 \mathrm{~mm}$ diameter of the cross-section (Fig. 7-10).

Experimental work: The experimental work involves preparing the testing machine (select a suitable power source, shaft hub dimension and material and brake system). Then preparing the shear pin specimens with (60, 90 and $120^{\circ}$ ) notch angle and $15 \mathrm{~mm}$ in diameter because it is difficult to make a testing machine for a $70 \mathrm{~mm}$ shear pin that used in the rolling machine. 


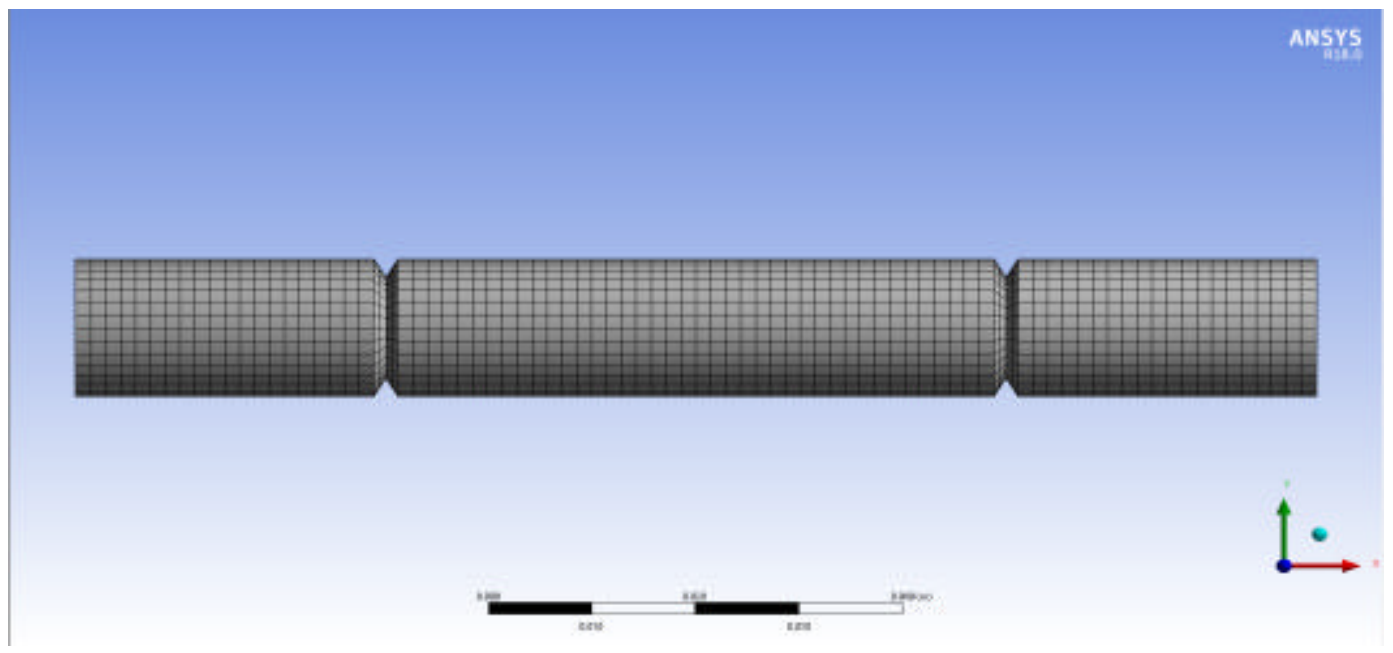

Fig. 10: The selected mesh of the manufactured shear pin

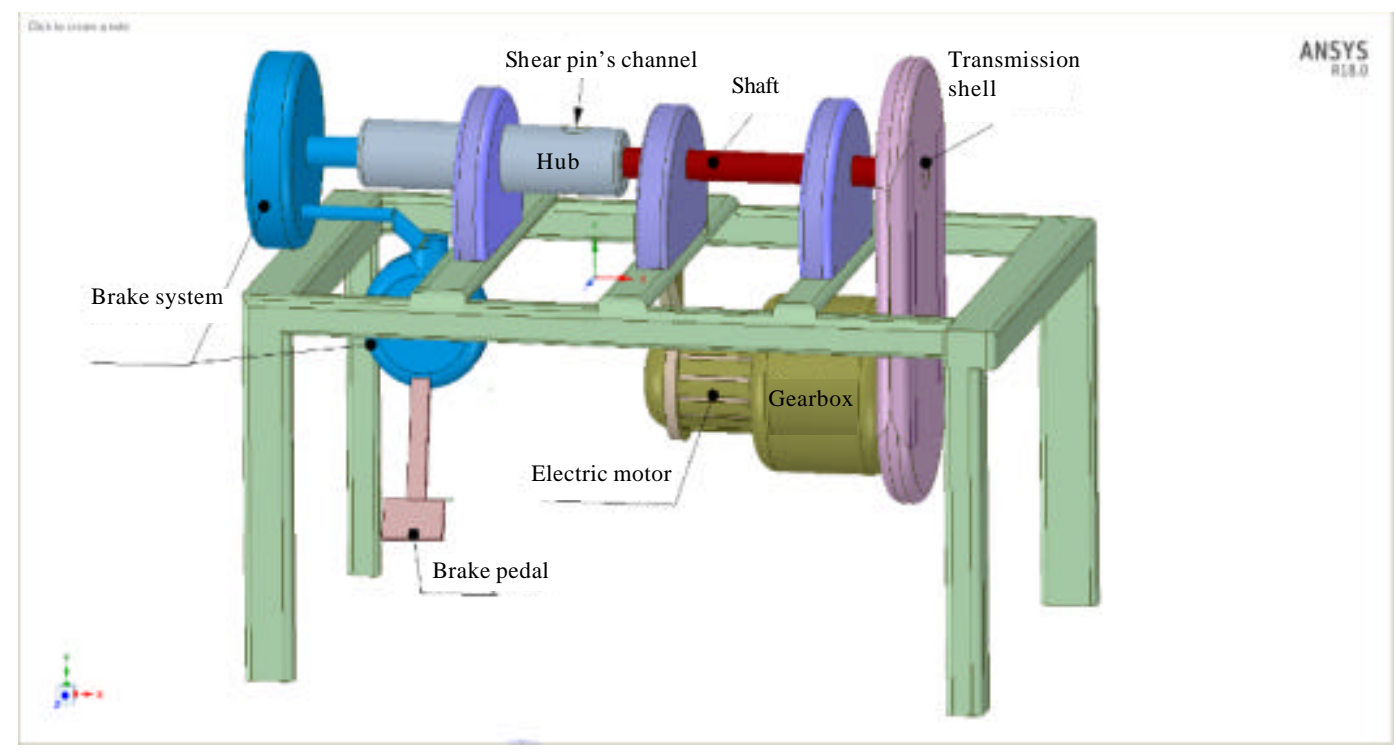

Fig. 11: 3D sketch of the testing machine

The fracture torque of these specimen is calculated by using measuring devices and some formulas and compared with the fracture torque produced by ANSYS Software for the same $15 \mathrm{~mm}$ diameter shear pin (Fig. 11 and 12). The procedures and the components that employed to manufacture the testing machine are:

Motor with gear box: Russian electric motor is utilized to supply the required power to the testing machine. It is $(50 \mathrm{~Hz})$ and $(1.5 \mathrm{~kW})$. A gearbox component (type $\mathrm{Mn} 02$ $108 \mathrm{~F}$ ) is attached with the electric motor to decrease the rotating speed generated by the motor.
- Transmission to translate the power from motor to the shaft-hub

- Shaft-hub component with drilled channel through them for the shear pin

- The cross section area's diameter of the shaft part is $(60 \mathrm{~mm}$ ) which equals the enter hub diameter

- Drum brake system to applied obstruction for the shaft-hub rotating to cause the shear pin fracture

- Supporters to hold the shafts and prevent the misalignment

- Switch to operate the machine and measure the voltage 


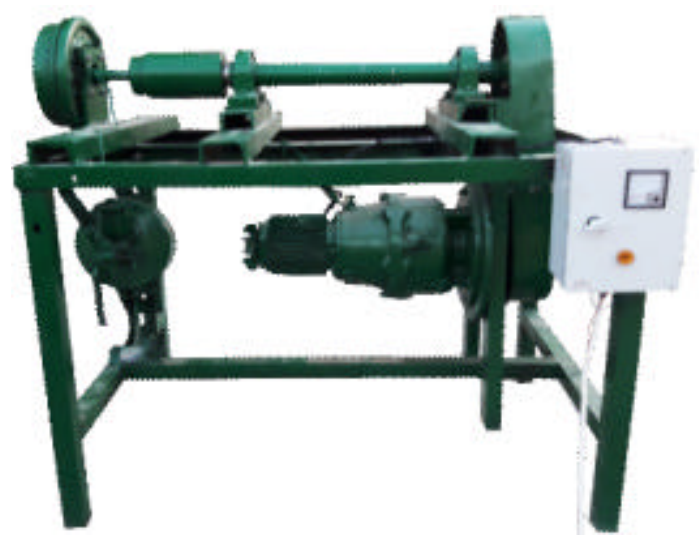

Fig. 12: Front view of manufactured machine

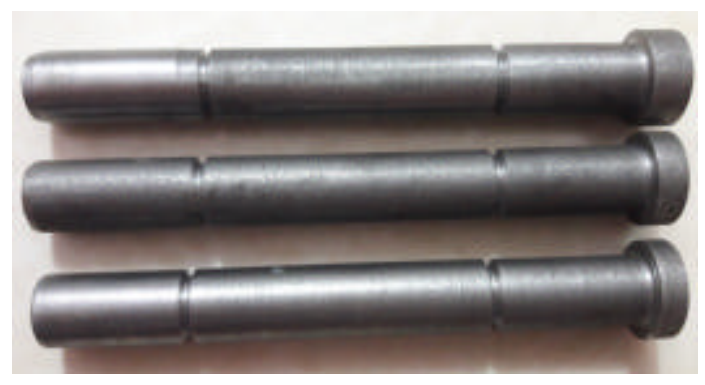

Fig. 13: The first group of manufactured shear pins

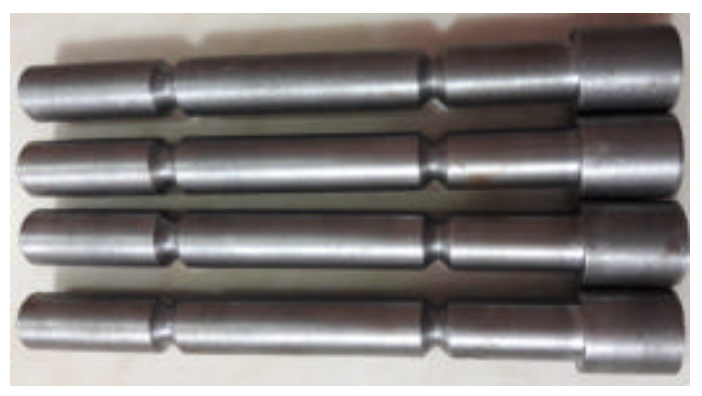

Fig. 14: The second group of manufactured shear pins

- Tachometer to measure the rotating shaft speed at the fracture

- Clamp-meters to measure the electric current

Testing process: After the lathing process, the gray cast iron rods are produced. Where the lathe machine makes the diameter of the sample is $15 \mathrm{~mm}$. There are three groups of the prepared shear pin: the first group with $\left(60^{\circ}\right.$ notch angle, $2 \mathrm{~mm}$ notch depth) as shown in Fig. 13. The second with $\left(90^{\circ}\right.$ notch angle, $4 \mathrm{~mm}$ notch depth) as shown in Fig. 14 and the third with $\left(120^{\circ}\right.$ notch angle with $4 \mathrm{~mm}$ notch depth) as shown in Fig. 15.

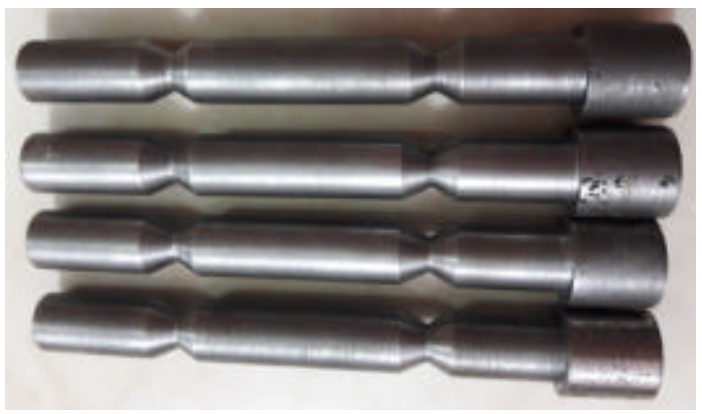

Fig. 15: The third group of manufactured shear pins

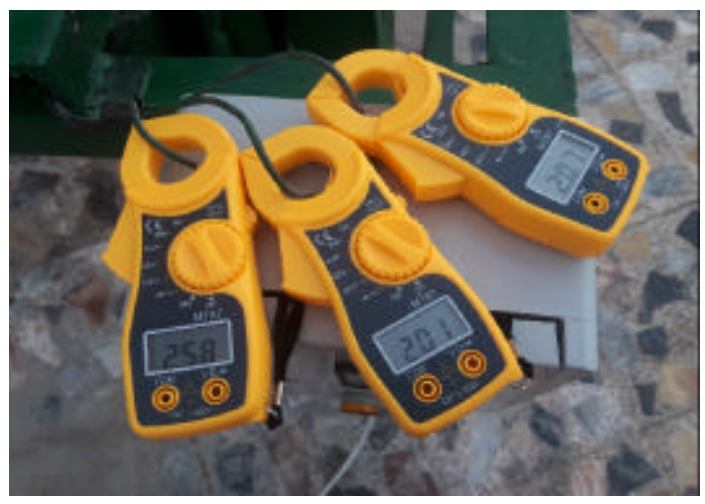

Fig. 16: The clamp-meters used to measure the electric current of the manufactured testing machine

The prepared shear pins are placed at the drilled channel. After the shear pin enters through the channel, the machine will operate causing shaft-hub rotating. Meanwhile, the brake paddle slowly pushes to fracture the shear pin. At this moment, the values appeared at the tachometer and clamp-meter are recorded. By recording the electric current by clamp-meter and the voltage of the motor $(\mathrm{V}=209 \mathrm{Volt})$, it is possible to compute the 3-phase electric motor power (Fig. 16):

$$
p=\sqrt{3} * I_{a y} * V * \text { The motor effecincy }
$$

Where:

$\mathrm{p}=$ The Power of the 3-phase electric motor

$\mathrm{I}=$ The electric current

$\mathrm{V}=$ The motor Voltage

The rotating speed at fracture records by the digital tacho-meter that locates in front of the hub and emits a laser ray on it. After calculating the speed and the power, the computing of the torque becomes possible by this Eq. 2 and 3 (Fig. 17): 


$$
\begin{gathered}
\mathrm{p}(\mathrm{Watt})=\mathrm{T}(\mathrm{N}) * \omega(\mathrm{rad} / \mathrm{sec}) \\
\omega(\mathrm{rad} / \mathrm{sec})=\frac{2 \pi *(\mathrm{rpm})}{60}
\end{gathered}
$$

Where

$\mathrm{T}=$ The Torque

- $=$ The rotating speed

This torque at fracture compares with the fracture torque obtained by ANSYS Software for the testing machine's shear pin.

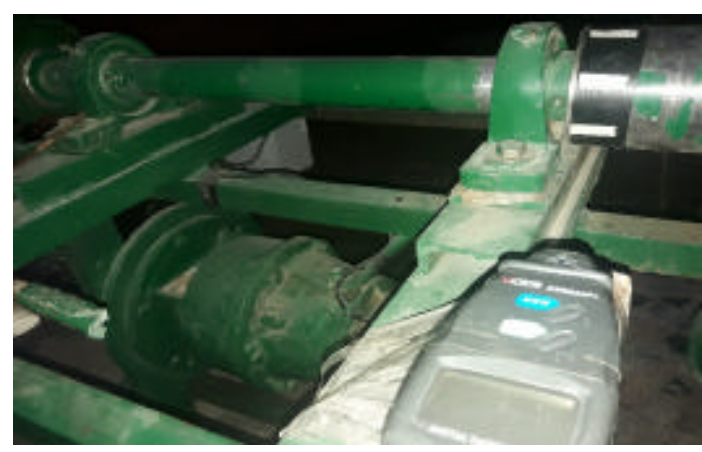

Fig. 17: Digital tachometer that used to measure the rotating speed through the testing process

\section{RESULTS AND DISCUSSION}

Numerical results of the testing machines shear pin: This pattern prepared for the testing machine to compare with the numerical data. For every sample, the fracture torque of the shear pin is calculated as shown in the following Table 2 and Fig. 18-20.

\section{Experiment results for the testing machine's shear pin:} The difference between the fracture torque for the same geometry specimens during the experimental work due to the internal defect of the material, a slight amount of non-accuracy of shear pin specimen's dimensions caused through the manufacturing process and the measuring processes by the tachometer and clamp-meter devices (Table 3 and Fig. 21). Some mistakes in manufacturing and measuring process, the material internal defects and some differences in the mesh by ANSYS Software are the reasons for these errors between the experimental and numerical data (Table 4).

Table 2: Numerical fracture torque for the shear pin patterns belong to the manuctured testing machine

\begin{tabular}{lc}
\hline Specimen & Numerical fracture torque $(\mathbb{N m})$ \\
\hline $2 \cdot=60^{\circ}, \mathrm{d}=2 \mathrm{~mm}$ & 304.3 \\
$2 \cdot=90^{\circ}, \mathrm{d}=4 \mathrm{~mm}$ & 297.9 \\
$2 \cdot=120^{\circ}, \mathrm{d}=4 \mathrm{~mm}$ & 370.0 \\
\hline
\end{tabular}

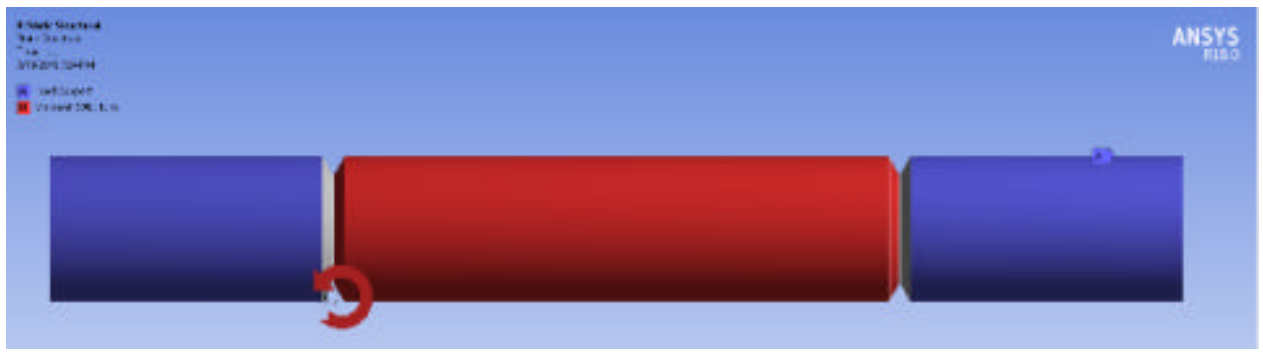

Fig. 18: The numerical torque fracture of the shear pin that used in manufactured testing machine $\left(2 \bullet=60^{\circ}, \mathrm{d}=2 \mathrm{~mm}\right)$

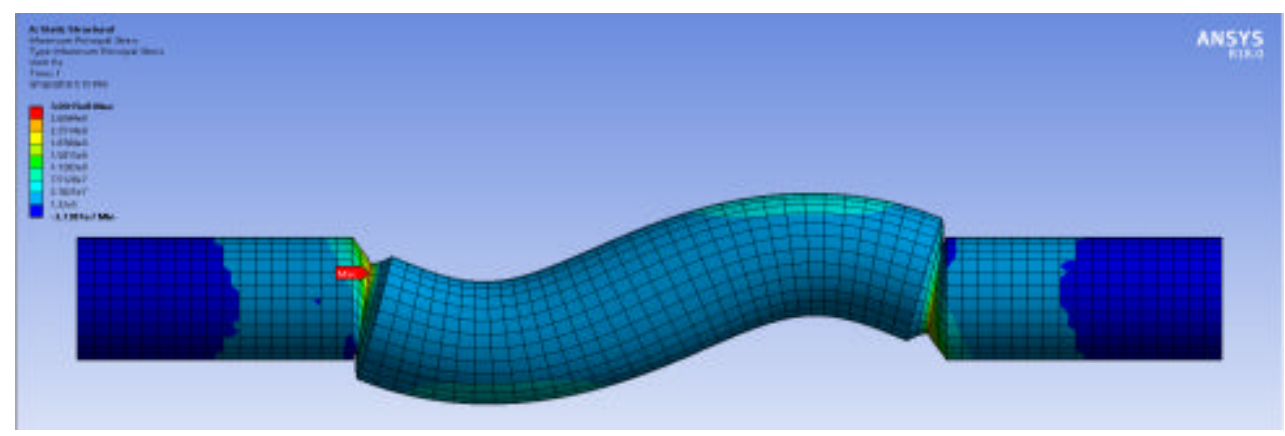

Fig. 19: The fracture stress the ( $300 \mathrm{MPa})$ that equals to the (UTS) of gray cast iron which caused by ( $304.3 \mathrm{~N} . \mathrm{m})$ 
J. Eng. Applied Sci., 14 (Special Issue 6): 9379-9395, 2019

Table 3: The experimental readings and computed fracture torque

\begin{tabular}{|c|c|c|c|c|c|c|}
\hline Notch dimensions (Shear pins) & $\mathrm{I}_{1}(\mathrm{Amp})$ & $\mathrm{I}_{2}(\mathrm{Amp})$ & $\mathrm{I}_{3}(\mathrm{Amp})$ & $\mathrm{I}_{\mathrm{av}}$ & Revolutions per minutes & Experimental fracture torque $(\mathrm{Nm})$ \\
\hline \multicolumn{7}{|l|}{$2 \cdot=60^{\circ}, \mathrm{d}=2 \mathrm{~mm}, \cdot=0$} \\
\hline Specimen 1 & 3.88 & 4.66 & 3.35 & 3.960 & 37.1 & 306.301 \\
\hline Specimen 2 & 3.98 & 3.23 & 3.25 & 3.660 & 35.3 & 297.507 \\
\hline Specimen 3 & 3.99 & 3.31 & 3.19 & 3.699 & 35.7 & 297.100 \\
\hline \multirow{2}{*}{\multicolumn{7}{|c|}{ 2. $=90^{\circ}, \mathrm{d}=\mathbf{4} \mathrm{mm}, \cdot=0$}} \\
\hline & & & & & & \\
\hline Specimen 5 & 4.66 & 4.23 & 4.25 & 4.446 & 42.8 & 301.600 \\
\hline Specimen 6 & 4.28 & 4.11 & 4.08 & 4.189 & 41.7 & 288.090 \\
\hline Specimen 7 & 4.98 & 3.72 & 3.76 & 4.360 & 41.3 & 300.100 \\
\hline Specimen 8 & 5.08 & 3.74 & 3.68 & 4.390 & 43.2 & 292.050 \\
\hline \multicolumn{7}{|l|}{$2^{\circ}=120^{\circ}, \mathrm{d}=4 \mathrm{~mm}, \cdot=0$} \\
\hline Specimen 9 & 3.11 & 1.79 & 1.99 & 2.450 & 31.5 & 378.660 \\
\hline Specimen 10 & 4.88 & 3.32 & 3.21 & 4.110 & 31.5 & 374.500 \\
\hline Specimen 11 & 3.69 & 4.66 & 3.63 & 4.160 & 32.8 & 364.000 \\
\hline Specimen 12 & 4.24 & 4.01 & 3.83 & 4.080 & 31.0 & 378.000 \\
\hline
\end{tabular}

Table 4: The experimental and numerical fracture torques $(\mathrm{Nm})$ with error percent

\begin{tabular}{lrrr}
\hline Specimens & Experimental fracture torque $(\mathrm{Nm})$ & Numerical fracture torque $(\mathrm{Nm})$ & Error $(\%)$ \\
\hline 1 & 306.301 & 304.3 & 0.657 \\
2 & 297.507 & & 2.234 \\
3 & 297.100 & & 2.360 \\
4 & 307.030 & 297.9 & 0.897 \\
5 & 301.600 & & 1.240 \\
6 & 288.090 & & 3.290 \\
7 & 300.100 & & 0.738 \\
8 & 292.050 & 370.0 & 1.970 \\
9 & 378.660 & & 2.340 \\
10 & 374.500 & & 1.216 \\
11 & 364.000 & & 1.620 \\
12 & 378.000 & & 2.162 \\
\hline
\end{tabular}

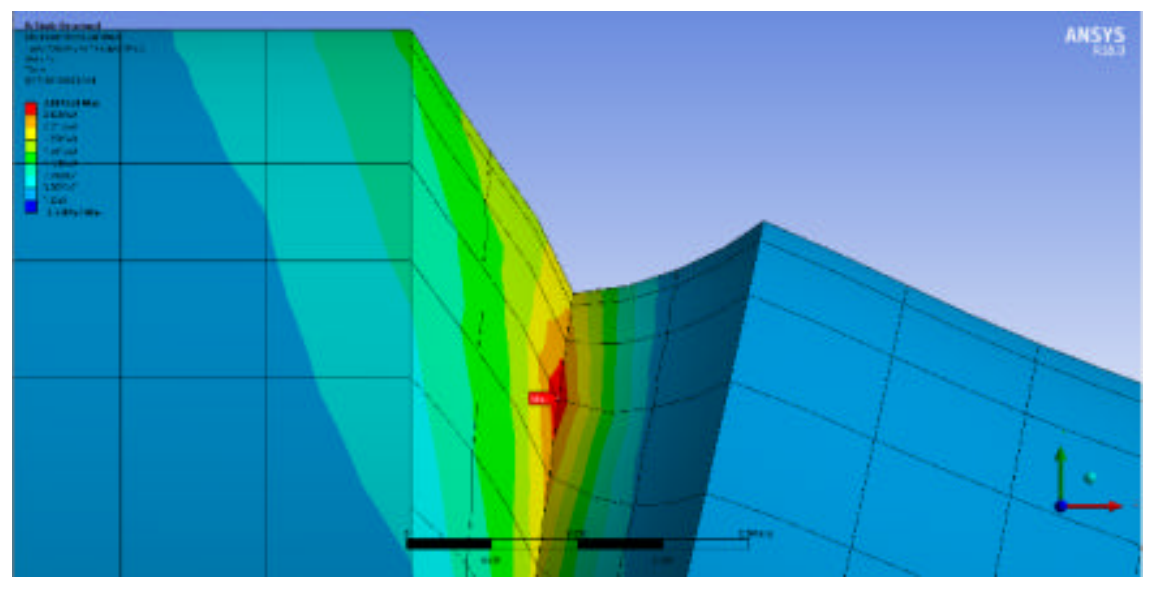

Fig. 20: Stress concentration at the notch tip radius for the shear pin specimen with $\left(2 \bullet=60^{\circ}, \mathrm{d}=2 \mathrm{~mm}\right)$

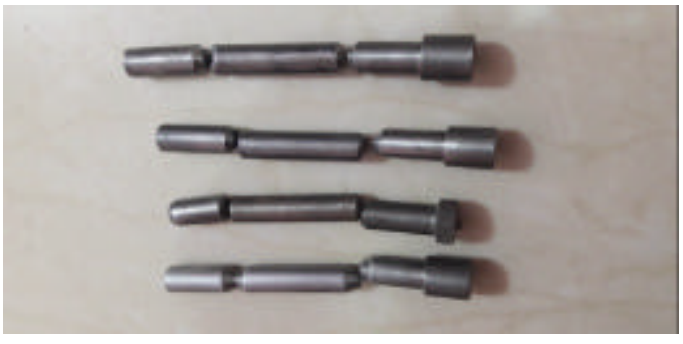

Fig. 21: Samples of shear pins fractured by the testing machine
Numerical results for the rolling machine's shear pin: After the previous validation between the experimental and numerical fracture torques for the testing machine's shear pin, the fracture torques of rolling machine's shear pin will explain. After that some samples of the ANSYS specimens for fracture torques and stress distributions for different notch geometries will present angles, notch depths and notch tip radii (Table 5 and Fig. 22-27).

\section{The effect of notch geometries}

The effect of notch angle: It is obvious that the magnitude of fracture torque has directly proportional to the notch 


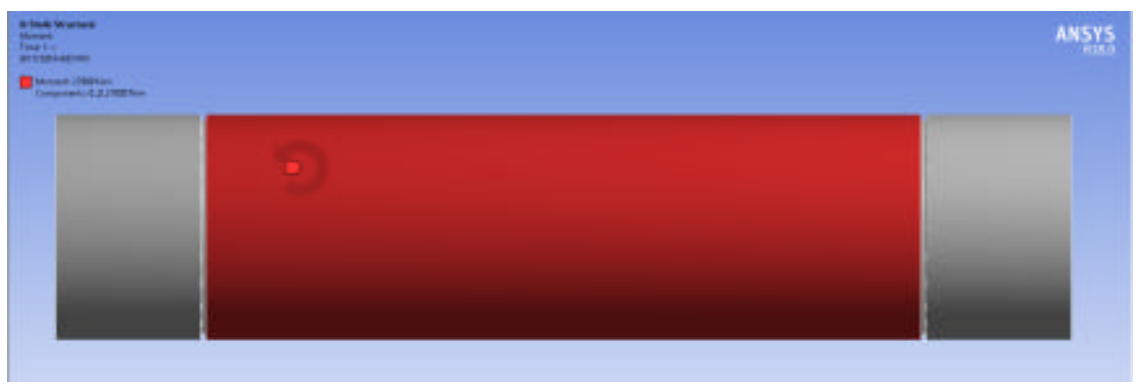

Fig. 22: Fracture torque of $\left(2 \bullet=30^{\circ}, \mathrm{d}=2, \bullet=0.5\right)$ compute by ANSYS to equal $(27 \mathrm{kNm})$

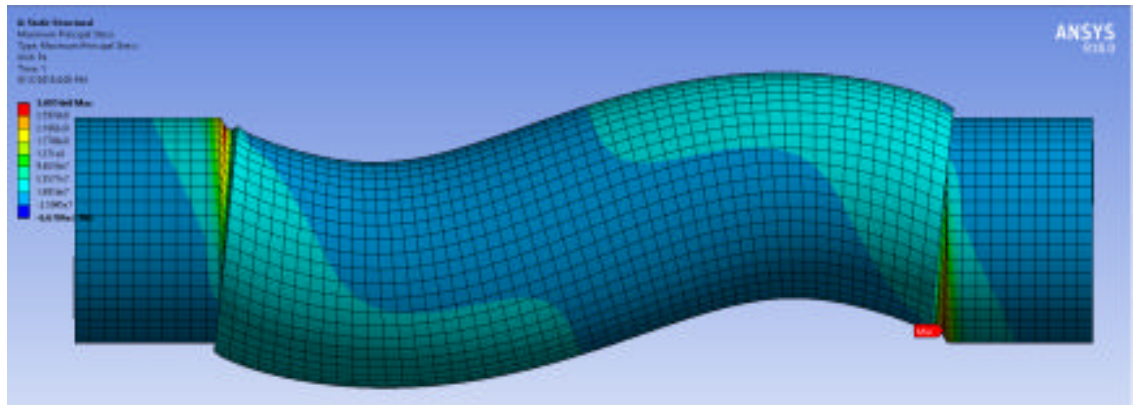

Fig. 23: Fracture stress $(300 \mathrm{MPa})$ that caused by $(27 \mathrm{kNm})$ for $\left(2 \bullet=30^{\circ}, \mathrm{d}=2, \bullet=0.5\right)$ and the stress distribution at fracture

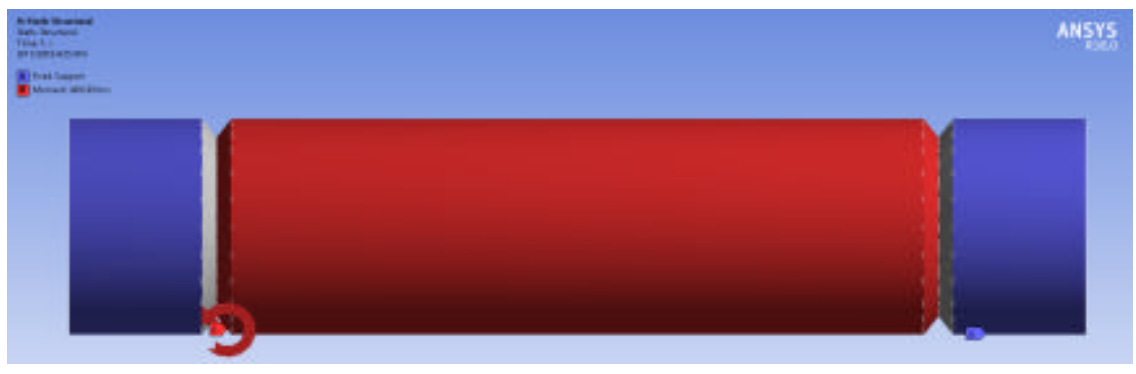

Fig. 24: Fracture torque of $\left(2 \bullet=74^{\circ}, \mathrm{d}=6, \bullet=0\right)$ compute by ANSYS to equal $(40.12 \mathrm{kNm})$

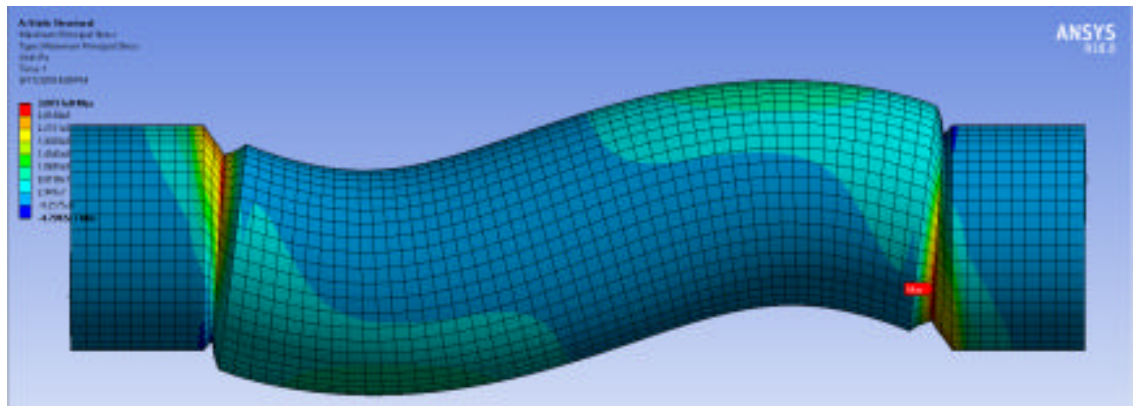

Fig. 25: Fracture stress $(300 \mathrm{MPa})$ that caused by $(40.12 \mathrm{kNm})$ for $\left(2 \bullet=74^{\circ}, \mathrm{d}=6, \bullet=0\right)$ and the stress distribution at fracture 


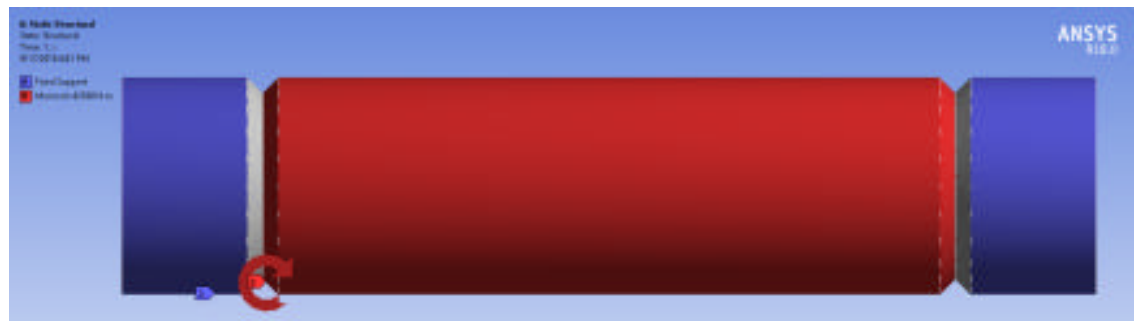

Fig. 26. Fracture torque of $\left(2 \bullet=90^{\circ}, \mathrm{d}=5, \bullet=0\right)$ compute by ANSYS to equal $(40.12 \mathrm{kNm})$

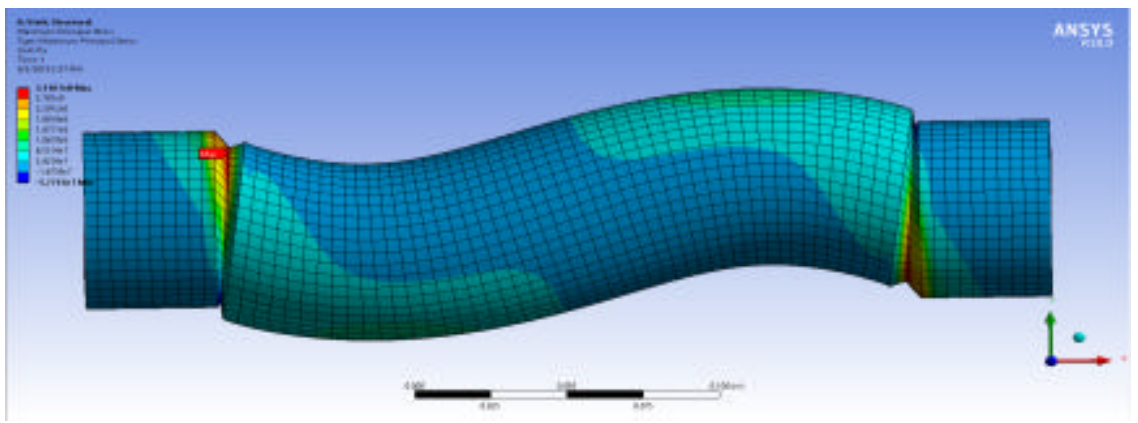

Fig. 27: Fracture stress that caused by $(40.12 \mathrm{kNm})$ for $\left(2 \bullet=74^{\circ}, \mathrm{d}=6, \bullet=0\right)$ and the stress distribution at fracture

Table 5: Fracture torque of the rolling machine's shear pin for different notch

\begin{tabular}{|c|c|c|c|c|}
\hline \multirow{2}{*}{$\begin{array}{l}\text { Notch depth/Tip } \\
\text { radius on } \mathrm{mm}) / \\
\text { (notch }(\mathrm{mm})\end{array}$} & \multicolumn{4}{|c|}{ Fracture torque $(\mathrm{kNm})$} \\
\hline & $30^{\circ}$ & $60^{\circ}$ & $74^{\circ}$ & $90^{\circ}$ \\
\hline \multicolumn{5}{|l|}{2} \\
\hline 0.00 & 21.11 & 27.60 & 31.60 & 34.12 \\
\hline 0.25 & 24.40 & 24.40 & 28.15 & 34.25 \\
\hline 0.50 & 27.00 & 29.42 & 28.82 & 34.80 \\
\hline 0.75 & 29.10 & 30.20 & 31.99 & 35.63 \\
\hline 1.00 & 29.45 & 29.89 & 31.97 & 35.40 \\
\hline \multicolumn{5}{|l|}{3} \\
\hline 0.00 & 19.34 & 30.80 & 31.63 & 36.90 \\
\hline 0.25 & 22.11 & 26.80 & 28.90 & 34.32 \\
\hline 0.50 & 25.60 & 29.79 & 31.10 & 34.70 \\
\hline 0.75 & 29.07 & 31.64 & 31.02 & 39.15 \\
\hline 1.00 & 29.91 & 31.60 & 36.30 & 39.72 \\
\hline \multicolumn{5}{|l|}{4} \\
\hline 0.00 & 19.24 & 31.59 & 39.43 & 40.72 \\
\hline 0.25 & 22.08 & 26.90 & 31.50 & 35.61 \\
\hline 0.50 & 27.39 & 31.60 & 34.70 & 36.40 \\
\hline 0.75 & 27.80 & 30.97 & 35.30 & 40.99 \\
\hline 1.00 & 28.79 & 30.32 & 36.80 & 40.87 \\
\hline \multicolumn{5}{|l|}{5} \\
\hline 0.00 & 19.17 & 30.40 & 39.43 & 42.58 \\
\hline 0.25 & 22.01 & 28.09 & 31.60 & 34.14 \\
\hline 0.50 & 27.38 & 31.98 & 36.60 & 35.80 \\
\hline 0.75 & 27.80 & 34.10 & 34.60 & 42.49 \\
\hline 1.00 & 28.75 & 34.00 & 36.00 & 42.65 \\
\hline \multicolumn{5}{|l|}{6} \\
\hline 0.00 & 18.70 & 34.40 & 40.12 & 43.21 \\
\hline 0.25 & 22.00 & 27.60 & 29.79 & 34.50 \\
\hline 0.50 & 27.25 & 31.37 & 31.10 & 37.89 \\
\hline 0.75 & 28.15 & 32.01 & 34.34 & 39.00 \\
\hline 1.00 & 28.80 & 31.88 & 36.44 & 39.98 \\
\hline
\end{tabular}

angle values. Where at $90^{\circ}$, the value of fracture torque equals to $(34.12,36.9,40.72,42.58$ and $43.21 \mathrm{kNm})$ for $2-6$ notch depths, respectively. While corresponding values for $30^{\circ}$ are $(21.11,19.34,19.24,19.17$ and $18.6 \mathrm{kNm})$. So, it is clear that the fracture torque decrease at an increase of the notch angle due to the decrease in stress concentration at large angles where it usually locates in narrow structures. The largest fracture torque value for this range of angles and notch depths is 43.21 which belongs to $90^{\circ}$ and the least fracture torque value is 18.9.11 which belongs to $30^{\circ}$, for the same notch depth $(6 \mathrm{~mm})$. It means that by a reasonable change in angles, it is possible to change the fracture torque by more than 24 units.

The effect of notch depth: For angle $30^{\circ}$ when the proportion of the (notch base/notch depth) $<1$ : The higher the notch depth, the lower the fracture torque. At the notch tip radius equals 0 where the fracture torque values are $(21.11,19.34,19.24,19.17,18.7 \mathrm{kNm})$ for the notch depths $(2-6 \mathrm{~mm})$, respectively. In general for this angle, increase of notch depth causes a small amount of decreases in fracture torque value. The small volume of the the notch does not allow for an obvious range to show the effect of the notch depth. This restriction for the notch depth effect becomes clearer when the tip radius increases (Fig. 28 and 29). 


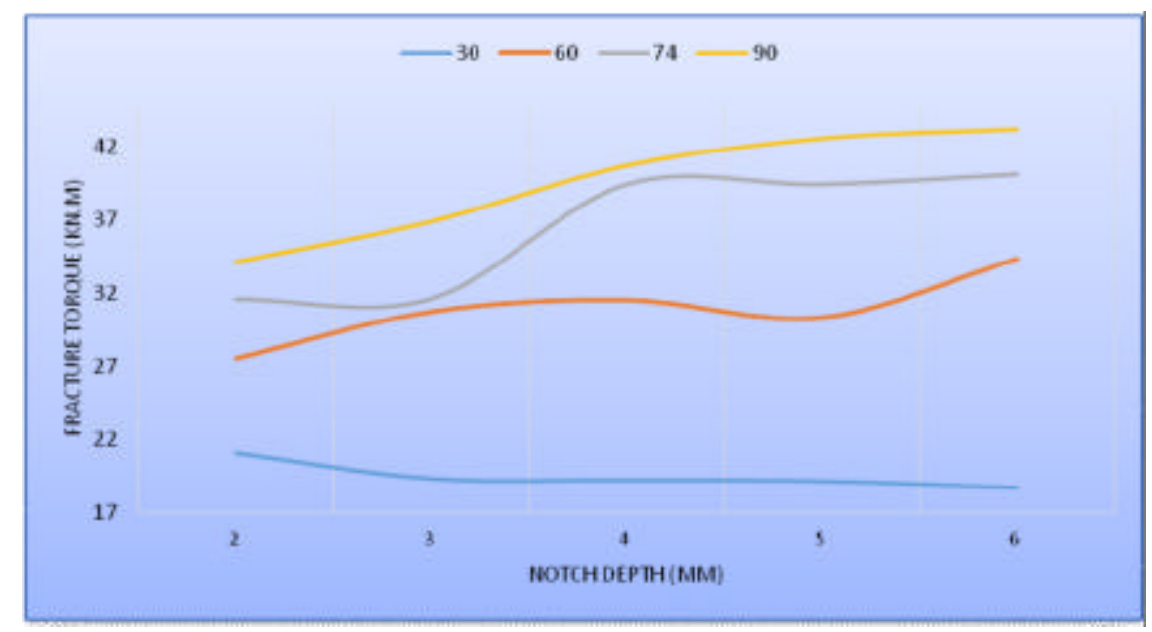

Fig. 28: The notch angle on the fracture torque

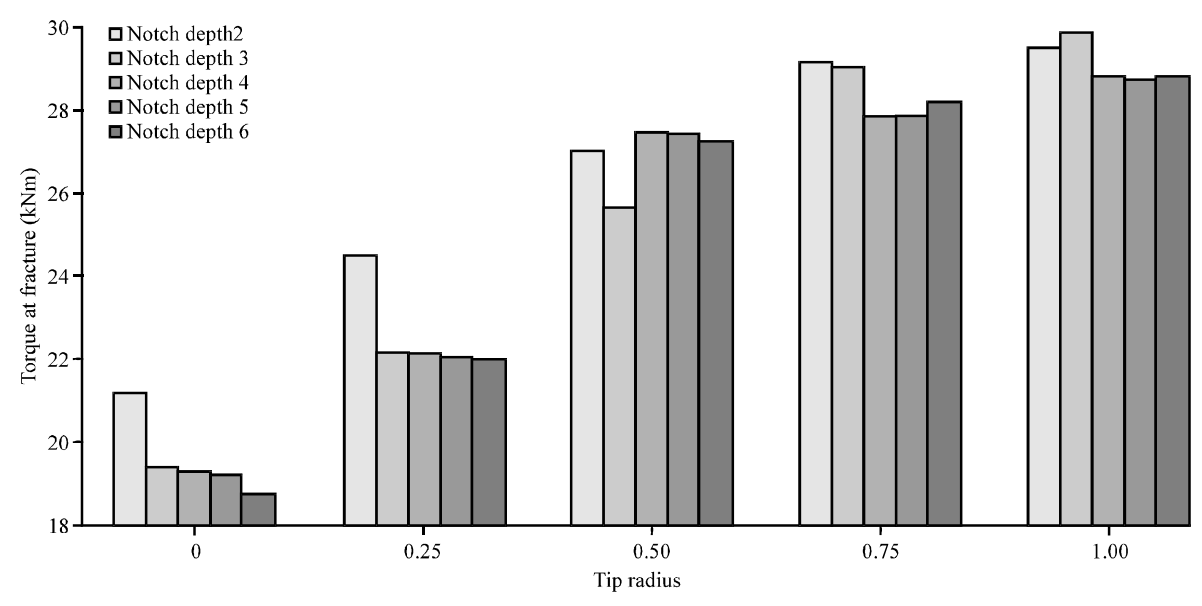

Fig. 29: The effect of the notch depth (mm) on the fracture torque of the shear pin (kN.m) for different tip radii of angle $30^{\circ}$. Every color represents on notch depth

In the case of $60^{\circ}$ and $74^{\circ}$ notch angle where the (Notch base/notch depth) proportion is $>1$ and $<2$ the fracture torque generally increased when the notch depth increased as shown in Fig. 30 and 31 where the notch shape begins to extend causing the decrease of the stress concentration. The magnitudes of fracture torque, for example, for the notch angle equals to $60^{\circ}$ are $(24.4,26.8$, $26.9,28.09,27.6 \mathrm{kNm})$ for $(2-6 \mathrm{~mm})$ notch depths with 0.25 notch tip radius, respectively. Where the fracture torque increases by 3 units when the notch depth increased by 4 units. The rest of the results involved in Table 5 .

At $90^{\circ}$ notch angle where (notch base/notch depth) $=2$, the notch depth increasing generally causes the fracture torque increasing as shown in Fig. 32. So, for - $=0.5$, the fracture torque values increased from $(34.8 \mathrm{kNm})$ at $(\mathrm{d}=2)-(37.89) \mathrm{kNm}$ at $(\mathrm{d}=6)$ and the rest results shown in Table 5 .
These results are acceptable with the results of Wu and Liu (2008) which show that the stress intensity factor mostly decreases with the notch opening angle but it often increases with the ratio value of Poisson's ratio. A very small change was showed when the opening angle $2 \cdot \cdot 30^{\circ}$, proving that the notch opening angle effect on the stress singularity near the notch root is not obvious.

The effect of notch tip radius: For the $30^{\circ}$ notch angle, the fracture torque increases as the tip radius increases because the stress concentration decreases in the wide areas. For example when $(d=2)$, the fracture torque increases from $(21.11) \mathrm{kNm}$ for 0 tip radius to $(29.45 \mathrm{kNm})$ for $1 \mathrm{~mm}$ tip radius. And when $(\mathrm{d}=6)$, the fracture torque increases from $(18.7 \mathrm{kNm})$ for 0 tip radius to $(28.8 \mathrm{kNm})$ for $1 \mathrm{~mm}$ tip radius. So, it is worth mentioning that when 


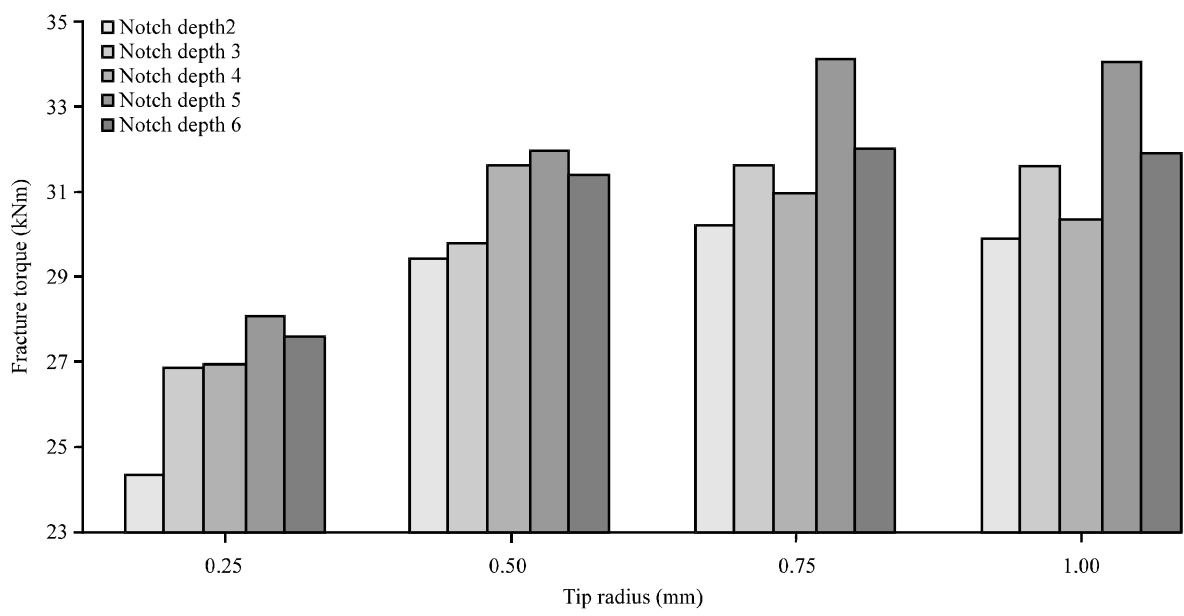

Fig. 30: The effect of the notch depth (mm) on the fracture torque of the shear pin for different tip radii of angle $60^{\circ}$. Every color represents one notch depth

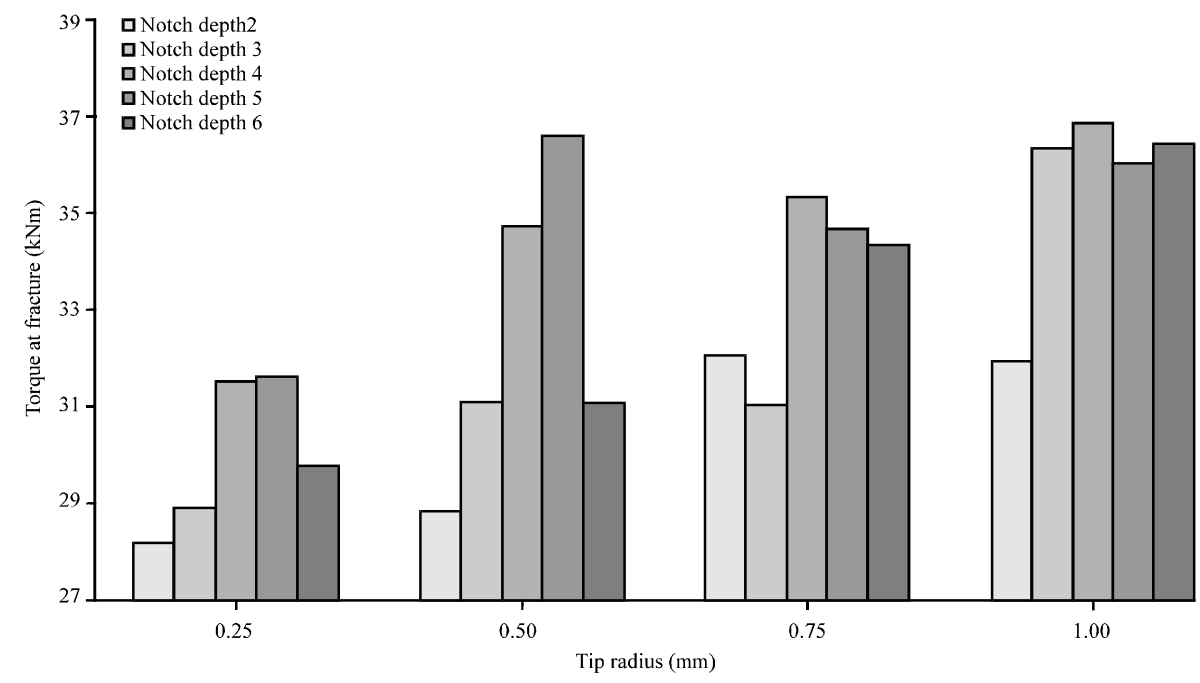

Fig. 31: The effect of the notch depth $(\mathrm{mm})$ on the fracture torque of the shear pin $(\mathrm{kNm})$ for different tip radii of angle $74^{\circ}$

the tip radius increases by 1 unit, the fracture torque increases by about 10 units. That means that in the same angle, the effect of the tip radius on the fracture torque is larger than the effect of the notch depth which increases the fracture torque by 3 units when a depth increases by 4 units for the same notch angle $30^{\circ}$. This is agreed with the Smith (2001) study that refers: the short range of root radius had a greater effect on stress intensity increasing rather than the flank angle. The following figures showed that and other data is shown in Table 5. For 60,74 and $90^{\circ}$ notch angles, the fracture torque has the minimum value at $\cdot=0.25$ and then begins to increase due to the decrease of the stress concentration.
Figure 32 explains the effect of the tip radius on the fracture torque of the shear pin for notch angle $=60^{\circ}$. Some values show different behavior of the general state in Fig. 32 and other. The reason for this different behavior belongs to the changes of the applied mesh. So, the general behavior is considered. The effect of tip radius for 74 and $90^{\circ}$ is explained in Fig. 31 and 32. Table 5 involves the rest of the data (Fig. 33 and 34).

The effect of the notch shape: In Table 6, five notch shapes which are selected to show their effects on the values of the maximum principal stress of the shear pin. The data are obtained by finite element method which performed by ANSYS Software. As shown in Fig. 35, when the notch depth (d) $7 \mathrm{~mm}$. 


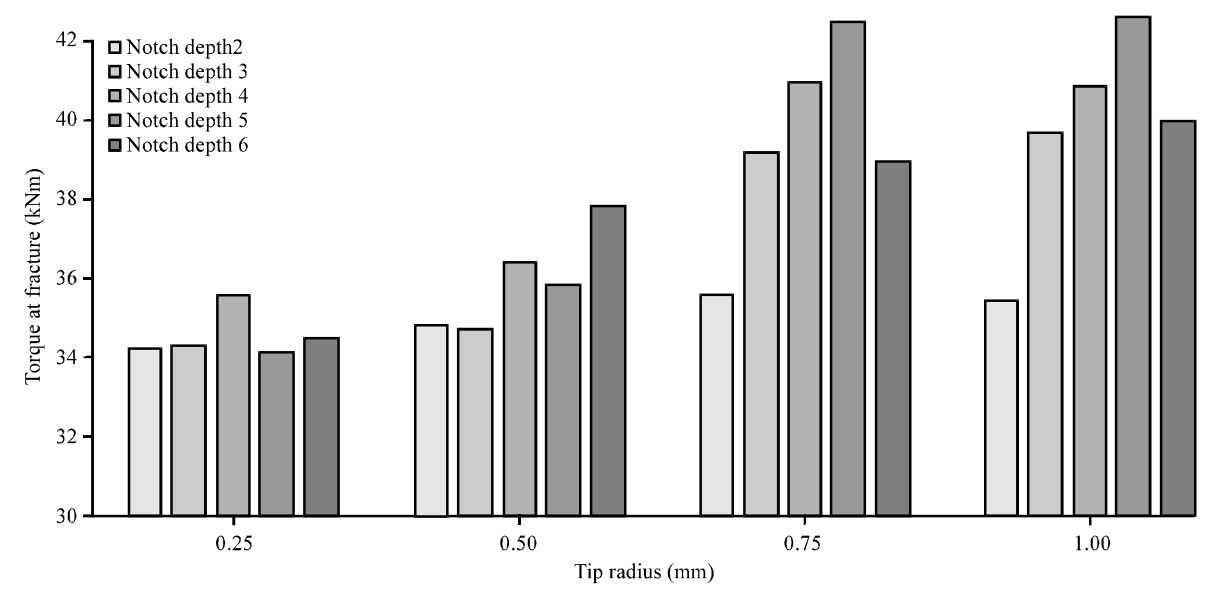

Fig. 32: The effect of the notch depth $(\mathrm{mm})$ on the fracture torque of the shear pin for different tip radii of angle $90^{\circ}$

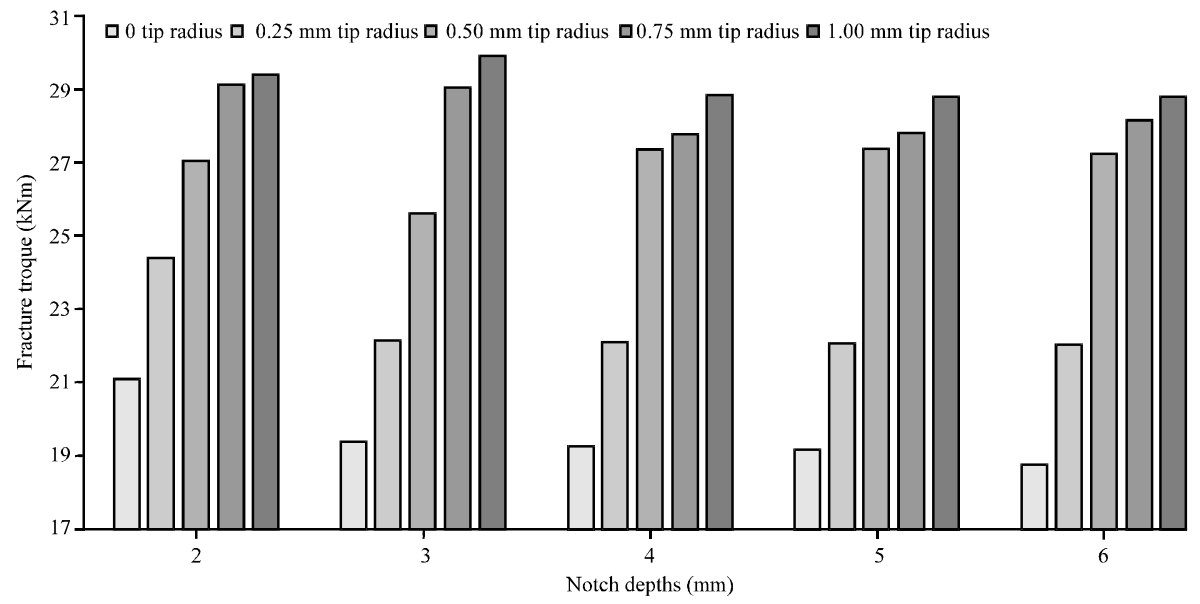

Fig. 33: The effect of the tip radius on the fracture torque of the shear pin for notch angle $=30^{\circ}$

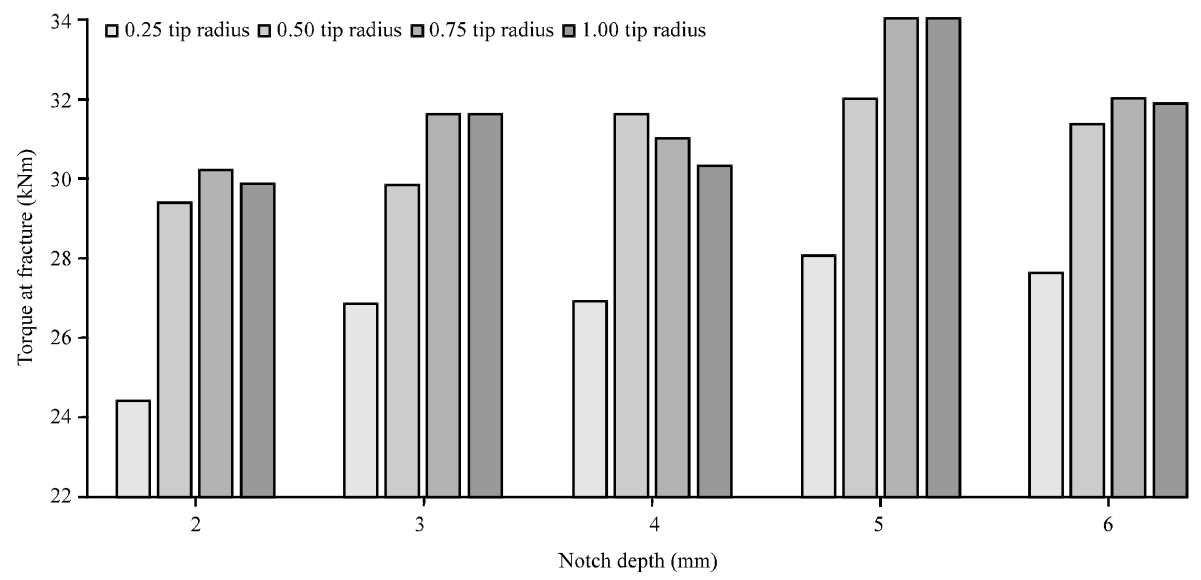

Fig. 34: The effect of the tip radius on the fracture torque of the shear pin for notch angle $=60^{\circ}$

- Trapezoidal notch shape has the maximum values of the maximum principal stress
- Square notch has the second level of the maximum principal stress values 


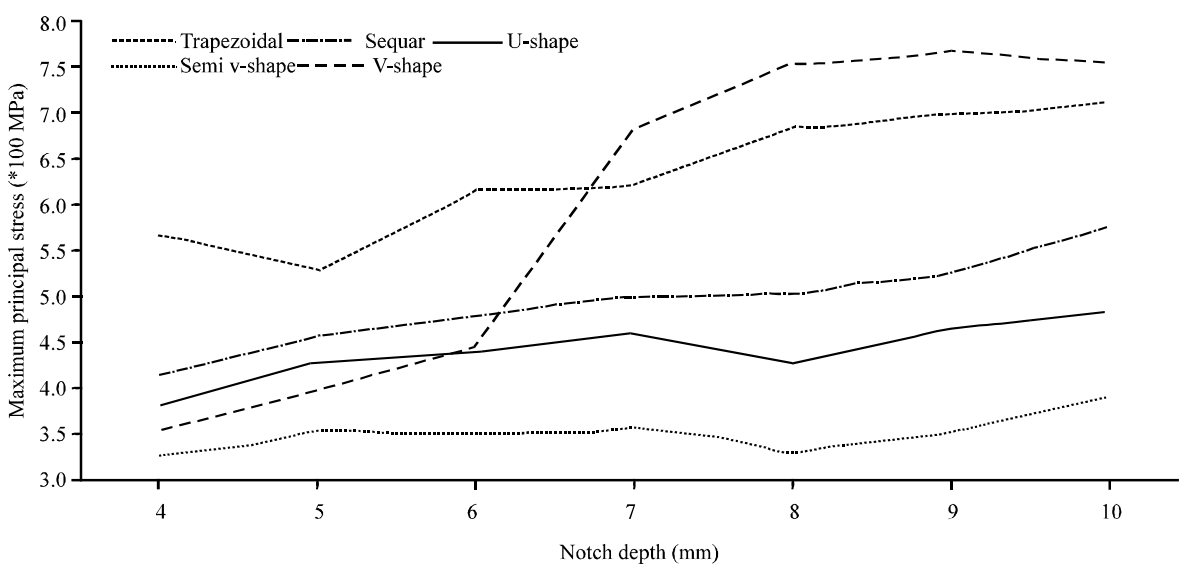

Fig. 35: The effect of the notch shape on the maximum principal stress

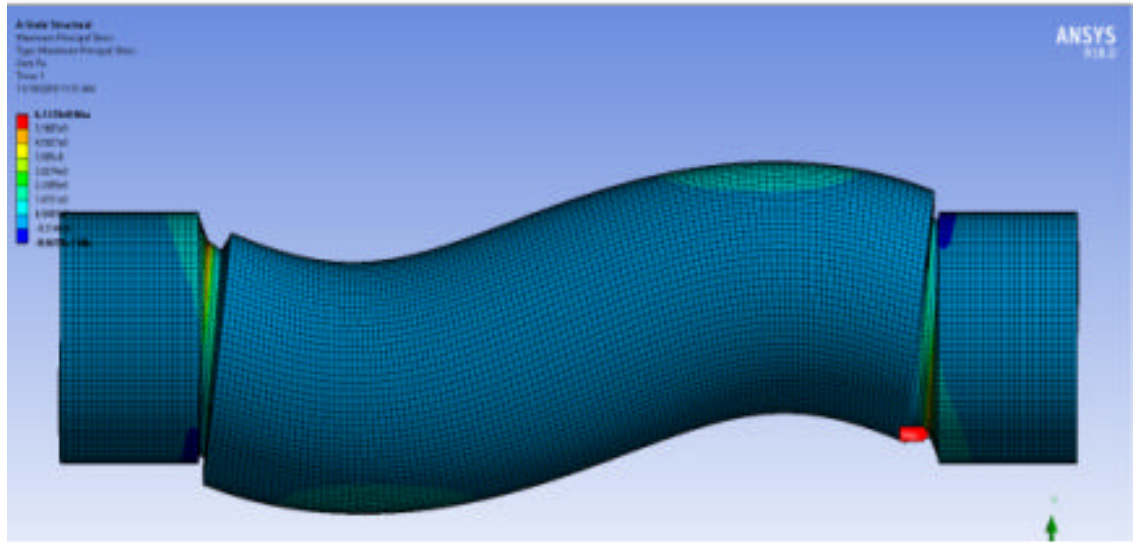

Fig. 36. Shear pin specimen with trapezoidal notch

- U-notch has the third level of the notch shape effect

- V-notch has the fourth level of the values of the maximum principal stress

- Semi-V notch has the minimum value of the maximum principal stress

When (d>7 mm): The V-notch shape become has the maximum values of the maximum principal stress and the others come after it in the same previous order as shown in Fig. 35 and 36.

So, there are various parameters contribute in these different results, the size of the notch, the stress intensity which increase in the sharp angle, the number of the angle and the location of the angle. Where with the small notch depths, the size of the notch is the most effective factor. So, the trapezoidal notch which have the maximum size has the maximum data of the maximum principal stress. But when the notch depth increases (more the $7 \mathrm{~mm}$ in this case) the stress intensity become the most important parameter. So, the V-notch has the largest values of the maximum principal stress. The semi V-notch still in the last level because the location of the angle is not at the middle but at the edge which change the stress distribution at the notch (Fig. 37-40).

Maximum principal stress for different material: Gray cast iron is selected in this study, due to its brittleness and low cost but many ANSYS specimens of the concerned shear pin are experienced from different material types. In Table 7 , the obtained results of maximum principal stress for samples that have the same geometry. It is noticed that there is no large difference in maximum principal stress in spite of its value is generally, increased as the ultimate tensile strength increases (Fig. 41) 
J. Eng. Applied Sci., 14 (Special Issue 6): 9379-9395, 2019

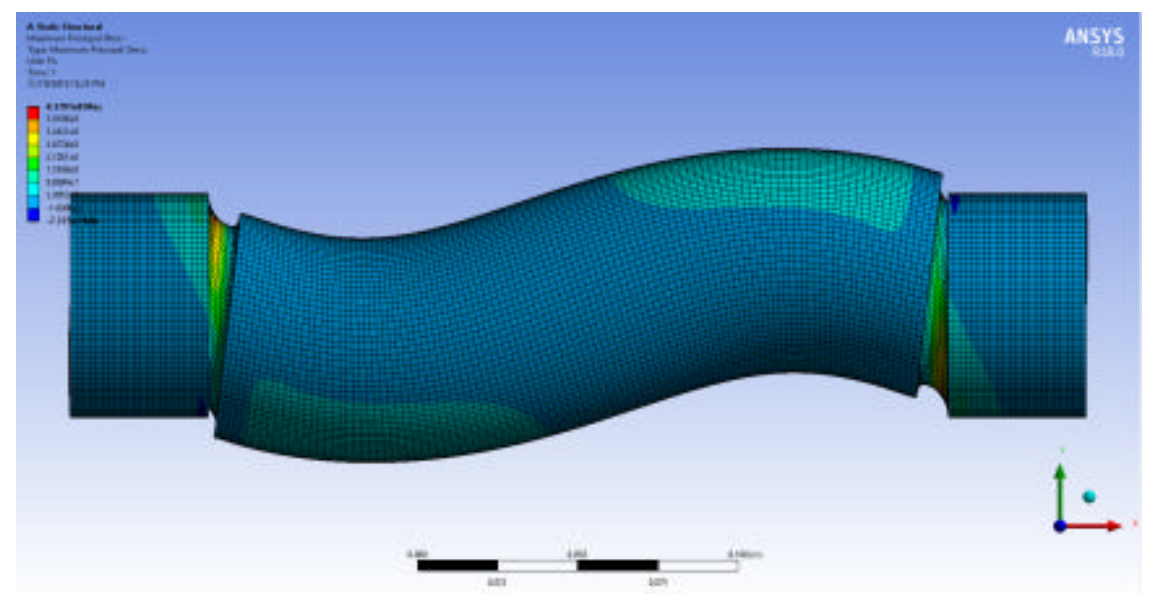

Fig. 37: Shear pin specimen with U-notch

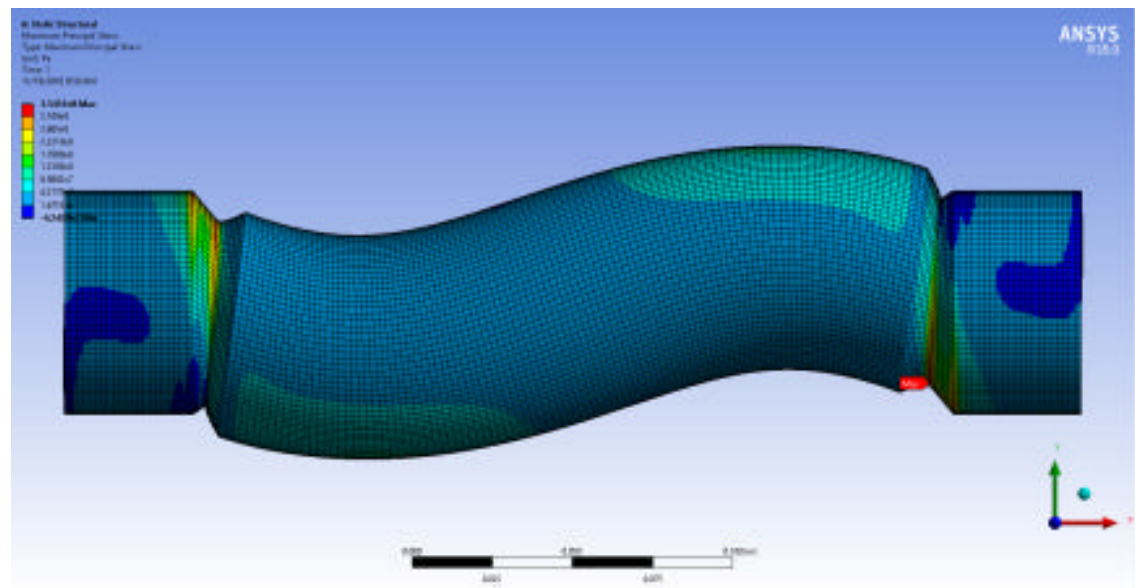

Fig. 38: Shear pin specimen with V-notch

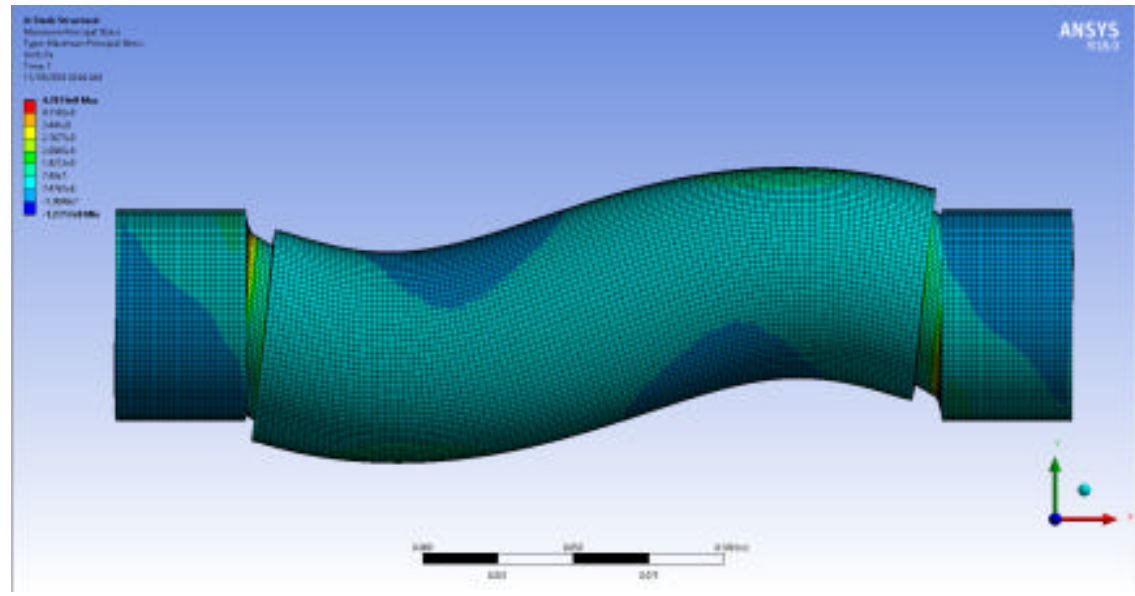

Fig. 39: Shear pin specimen with square notch 
J. Eng. Applied Sci., 14 (Special Issue 6): 9379-9395, 2019

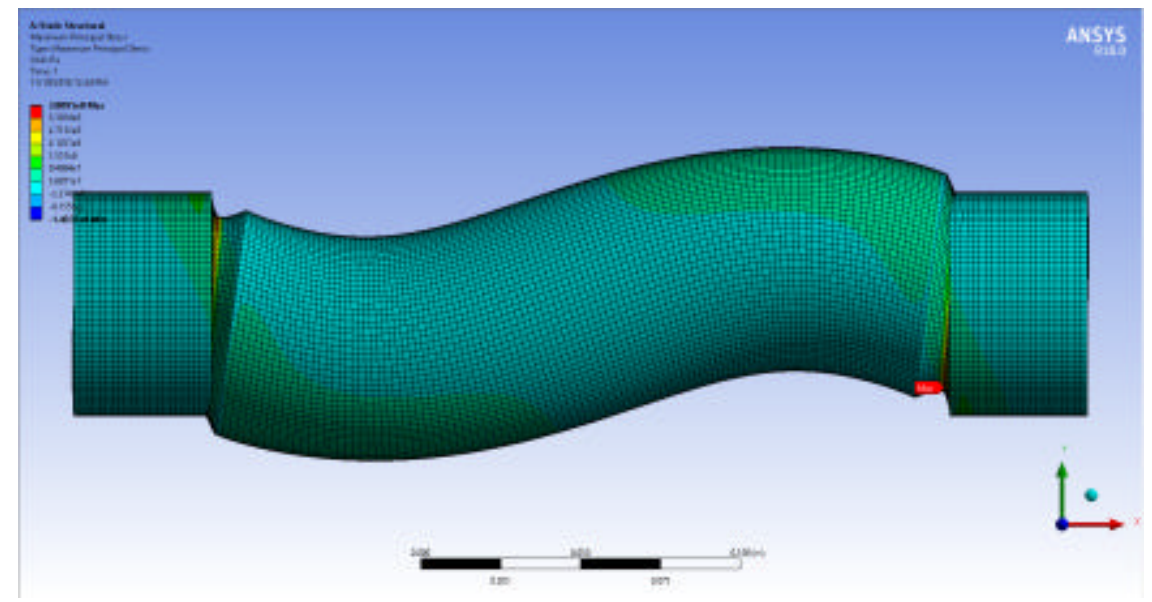

Fig. 40: Shear pin specimen with semi V-notch shape

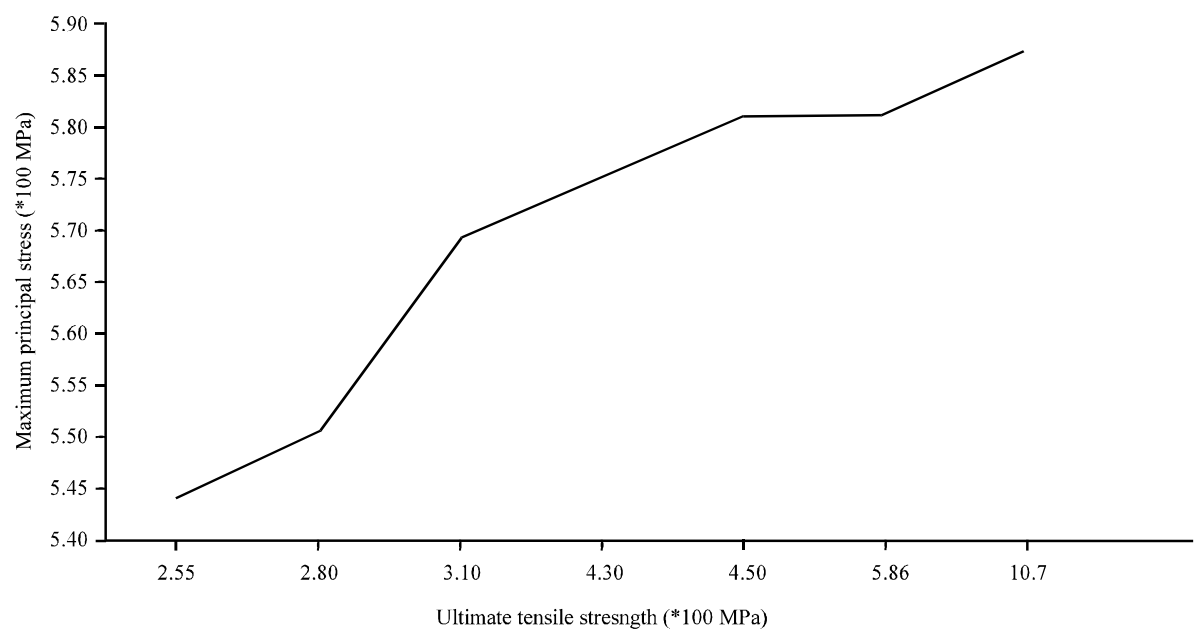

Fig. 41: The effect of ultimate tensile strength on the maximum principal stress

Table 6: Maximum principal stress for different angle shapes and notch depths

Maximum Principal stress (MPa)

\begin{tabular}{|c|c|c|c|c|c|}
\hline $\begin{array}{l}\text { Notch depth } \\
\text { (mm) }\end{array}$ & & & $\biguplus$ & & \\
\hline 4 & 355.1 & 327.6 & 379.7 & 415.4 & 565.2 \\
\hline 5 & 400.5 & 353.4 & 424.9 & 455.2 & 528.4 \\
\hline 6 & 445.0 & 348.9 & 437.9 & 478.7 & 613.7 \\
\hline 7 & 681.3 & 357.5 & 454.9 & 496.9 & 620.9 \\
\hline 8 & 751.0 & 329.4 & 425.4 & 502.1 & 679.4 \\
\hline 9 & 764.1 & 352.5 & 461.4 & 526.0 & 698.7 \\
\hline 10 & 753.2 & 389.0 & 482.8 & 575.1 & 713.3 \\
\hline
\end{tabular}

Table 7: Maximum principal stress for different material

\begin{tabular}{lcc}
\hline Materials & Ultimate tensile strength & Maximum principal stress \\
\hline Gray cast iron & 2.80 & 5.440 \\
Brass & 4.50 & 5.498 \\
Aluminum alloy & 3.10 & 5.671 \\
Copper alloy & 4.30 & 5.724 \\
Magnesium alloy & 2.55 & 5.780 \\
Stainless steel & 5.86 & 5.780 \\
Titanium alloy & 10.70 & 5.840 \\
\hline
\end{tabular}

\section{CONCLUSION}

The study involved preparing about 170 ANSYS specimens and 12 manufactured specimens to investigate the effect of notch geometry (angle, depth, tip radius, shape) on the fracture torque to be able to design and manufacture the rolling machine's shear pin in a company in Iraq. The notch dimensions that used by ANSYS for the rolling machine's shear pin $(70 \mathrm{~mm}$ cross-section area's diameter) are $\left(30,60,74,90,120^{\circ}\right)$ for notch angle, $(2-6 \mathrm{~mm})$ for notch depth and $(0,0.25,0.5,0.75,1 \mathrm{~mm})$ for tip radius. For experimental work shear pin $(15 \mathrm{~mm}$ cross-section diameter), the notch dimensions are $\left(2 \cdot=60^{\circ}, \mathrm{d}=2\right)$ for the first group of the specimens, $\left(2^{\bullet}=90^{\circ}, \mathrm{d}=4\right)$ for the second group and $\left(2^{\bullet}=120^{\circ}\right.$, $\mathrm{d}=4$ ) for the third. Consequently:

Good acceptable results are obtained between the numerical and experimental data with error percent does 
not exceeds (4\%). The study prepared a detailed tables serve as catalogue or designer's guide that presents a suitable geometry for any value of torque that is required by the rolling machine of the General Company for Copper and Mechanical Industries in Iraq. The effect of the notch geometry on the fracture torque is:

The fracture torque decreases when the notch angle decreases due to that the stress concentration usually increases at the narrow angles. The fracture torque increases when the notch depth increases for the notch angles $\left(60,74,90^{\circ}\right)$ but very small change is noticed for $\left(30^{\circ}\right)$. At the notch angle $\left(120^{\circ}\right)$, the highest stress concentration locates at the notch side edge not at the notch tip. The minimum fracture torque takes place at $0.25 \mathrm{~mm}$ tip radius and begin to increase with the increase in tip radius value.

The effect of the notch tip radius is larger than the effect of the notch depth. Where for the same angle, there is one case (for example) the tip radius increases by 1 unit causing the fracture torque increases by about 10 units but the notch depth increases by 4 units causing the fracture torque increases by 3 units. The notch shape that mostly presents the maximum values of the maximum principal stress is the trapezoidal. On the other hand, the minimum value of the maximum principal stress accomplishes are achieved with the semi $\mathrm{V}$-notch shape.

The maximum principal stress is not very sensitive to the ultimate tensile strength. A large increase in the ultimate tensile strength (from 280-1070 MPa) corresponds with a small increase in the maximum principal stress (from 540-584 MPa).

\section{RECOMMENDATIONS}

For future studies, we recommend examining. Different types of torque limiter for the rolling machine case that can be manufactured in Iraq. Various materials for the shear pin.

\section{REFERENCES}

Azevedo, C.R.D.F., D. Magarotto, J.A. Araujo and J.L.A. Ferreira, 2009. Bending fatigue of stainless steel shear pins belonging to a hydroelectric plant. Eng. Fail. Anal., 16: 1126-1140.

Aziz, S.S., 2018. Improvement the hardness and wear resistance of gray cast iron using $\mathrm{Nd}$ - YAG laser treatment. University of Anbar, Ramadi, Iraq.

Jha, A.K., K. Sreekumar and M.C. Mittal, 2008. Metallurgical studies on a failed EN 19 steel shear pin. Eng. Fail. Anal., 15: 922-930.

Sankar, S., M. Nataraj and V.P. Raja, 2011. Failure analysis of shear pins in wind turbine generator. Eng. Fail. Anal., 18: 325-339.

Smith, E., 2001. Fracture initiation at the root of a sharp groove: Description in terms of $\mathrm{Kr}-\mathrm{Lr}$ failure assessment curves. Intl. J. Eng. Sci., 39: 355-360.

Smith, M., F. Fisher, M. Romios and O.S. Es-Said, 2007. On the redesign of a shear pin under cyclic bending loads. Eng. Fail. Anal., 14: 138-146.

$\mathrm{Wu}, \mathrm{Z}$. and Y. Liu, 2008. Analytical solution for the singular stress distribution due to $\mathrm{V}$-notch in an orthotropic plate material. Eng. Fract. Mech., 75: 2367-2384. 